\title{
Correction to: Analysis of neurotransmitter levels in addiction-related brain regions during synthetic cathinone self-administration in male Sprague-Dawley rats
}

\author{
Julie A. Marusich ${ }^{1}$ - Elaine A. Gay ${ }^{1}$ • Bruce E. Blough ${ }^{1}$
}

Published online: 17 May 2019

(C) Springer-Verlag GmbH Germany, part of Springer Nature 2019

\section{Correction to: Psychopharmacology}

https://doi.org/10.1007/s00213-018-5011-8

In Figure 3, in the amygdala panel (upper left panel), the HVA and NE levels are switched. The correct figure is shown below.

Publisher's note Springer Nature remains neutral with regard to jurisdictional claims in published maps and institutional affiliations.

The online version of the original article can be found at https://doi.org/ $10.1007 / \mathrm{s} 00213-018-5011-8$

Julie A. Marusich

jmarusich@rti.org

1 Center for Drug Discovery, RTI International, 3040 Cornwallis Rd, 136 Hermann, Research Triangle Park, NC 27709, USA 

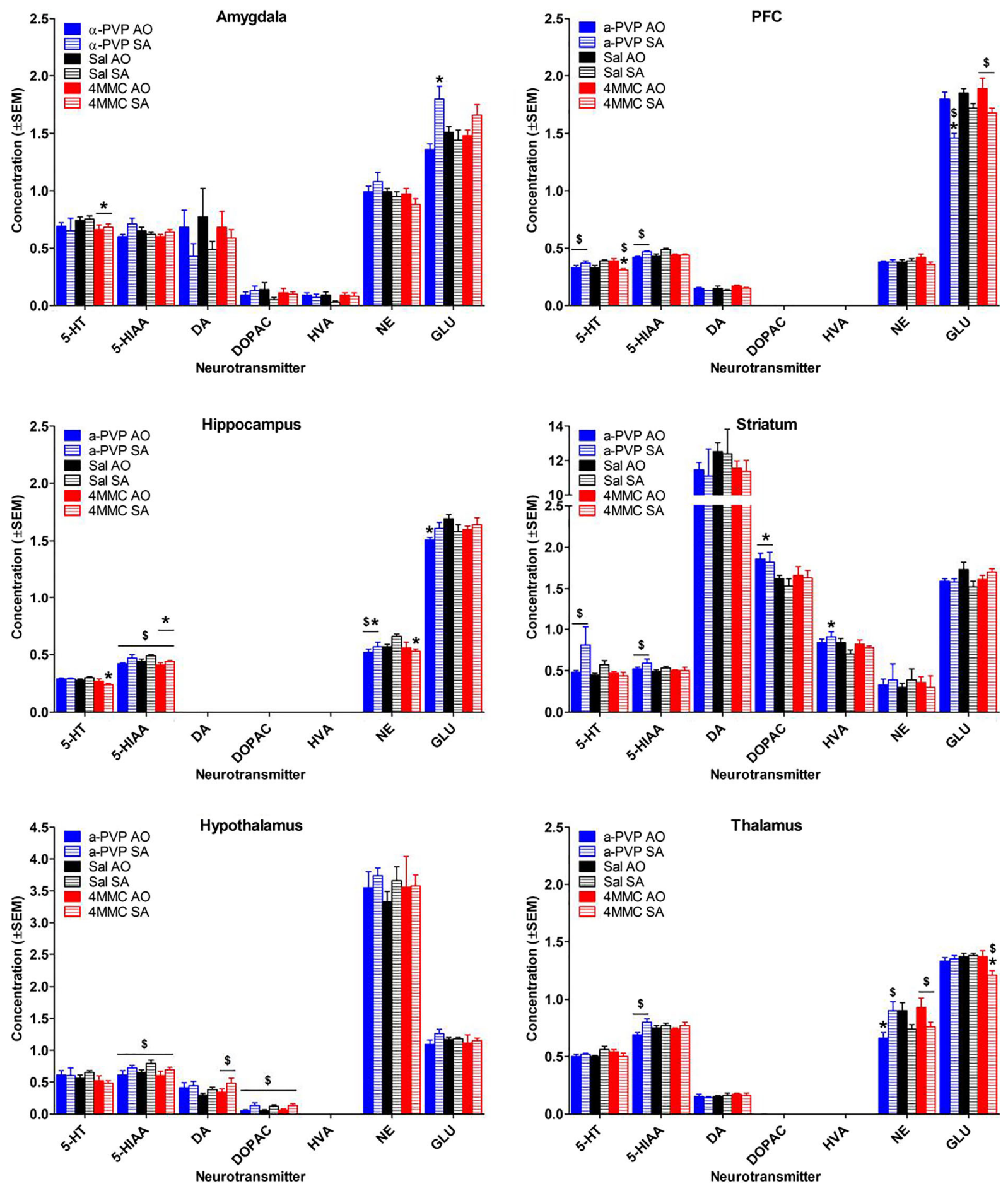